1449

\section{WHERE DOES THE TIME GO? IDENTIFYING DELAYS IN TRANSFER OF PATIENTS WITH TIME CRITICAL NEUROSURGICAL EMERGENCIES TO ENABLE EFFECTIVE CHANGE}

\author{
C. Koyalakonda, K. Parkins, S. Mahoney, \\ N. Shetty, S. McCoy
}

Paediatric Intensive Care, Alder Hey Children's NHS Foundation Trust, Liverpool, UK

Background and Aims: Joint Statement from the Society of British Neurological Surgeons (SBNS) and the Royal College of Anaesthetists (RCoA) states the need for clear instructions for referral and management of time critical neurosurgical emergencies to avoid any delays which could cause harm. Following a patient death we conducted an audit to identify delays in transfer. Lessons learnt from audit will be used to improve our local guideline.

Method: Retrospective case note review of PICU patients with time critical neurosurgical emergency who died between 2004-2010. Any delays in transfer were identified

Results: 12 patients: causes of raised intracranial pressure included trauma (2), acute intracranial bleed (4), intracerebral abscess (2), new tumour (2), blocked VP shunt (2). Median time from referral to retrieval team (local or regional) leaving to transfer patient to PICU was 2.625 hours. Delays identified: delay in CT (5/12); referring unit asked 'can you bring?' (10/12); local team unable to bring (6/12); 'stay \& play' not 'scoop \& run' (8/12); late involvement neurosurgeon (2/12); geographical factors (2/12); difficulties with CT image transfer $(3 / 12)$

Conclusion: Without clear guidelines including explicit instructions on how to perform a time critical transfer, transfer teams (local or specialised) will adopt a safe, modified 'stay \& play' policy which can result in delays which may lead to patient harm. Effecient CT image transfer between referring unit and lead centre to allow neurosurgeon to determine whether a patient needs a time critical transfer important . Education/training on new guidelines and re-audit of transfers needed.

\section{PAEDIATRIC SPECIALISED TRANSPORT TEAMS IN THE CENTRAL REGION OF PORTUGAL}

\author{
A. Dias, A. Luz, L. Carvalho, J. Farela Neves
}

Paediatric Intensive Care Unit, Hospital Pediátrico de Coimbra, Coimbra, Portugal

Background: Paediatric Specialised Transport (PST) teams play a key role in the success of interfacility transport (IT) of seriously ill children. In Portugal these teams have been recently implemented. The aim is to characterize PST in the Central Region of Portugal.

Methods: Retrospective analysis of PST ( $\geq 28$ days and < 15 years) from 2005 to 2009. Data was collected from the hospital IT database.

Results: IT was requested 433 times and 426 children were transported ( 5 died before team arrival and 2 didn't meet criteria for transport); median age was 11 months and $51 \%$ were infants. The main diagnostic groups were: cardiac disease 106 (25\%), surgery $65(15 \%)$, respiratory failure $62(14 \%)$ and trauma $47(11 \%)$. Half of IT was requested by health services of our city (Paediatric Hospital 28\%; Adult Care Center 18\%) and $40 \%$ was requested by Referring Hospitals ( $\mathrm{RH})$. The main destinations were Paediatric Hospital (290 - 68\%), mainly PICU (89\%); diagnostic exams centers (89-21\%) and NICUs $(21-5 \%)$. Most children were stable or improved during transport (96\%); instability was observed in $3 \%$ and less than $1 \%$ worsened their condition. There was no mortality during IT. During transport $78 \%$ of children required procedures/ therapies. The main procedures performed by transport practitioners were: vascular cannulation $(86 \%)$, mechanical ventilation (39\%), sedative $(16 \%)$ and inotropic agents (9\%) administration.

Conclusions: PST has provided a safe and early care of critical ill children at $\mathrm{RH}$. Their stabilization before reaching a Tertiary Paediatric Facility has been associated with better outcome. 